the preceding occupy absut five pages of the journal, and are specimens of what Copland so aptly denominated the "printed records of little value," or, it may be added, of no value at all. This worthy, we perceive, has another project in view, no less than to establish " an annual meeting of the medical grarluates of Edinburgh, to be held in London." The meeting he says, "may be merely a dinner," " and," he continues, " it cannot be difficult to name a fit president or chairman for the day," meaning, we suppose, himself. This we doubt not is an attempt to resuscitate the departed Decad, and therefore caution all respectable plysicians of the degrarlation which awaits them should tliey fall into the advocate's scheme.

\section{FOREIGN DEPARTMENT.}

\section{ANAIYYSIS OF FOREIGN MEDICAL JOURNALS.}

\section{ARCHIVES GENERALES DE MEDICINE.}

Memoir on Sciatica, or femoro-poptiteal Neuralgia, by J.H. Réveillé Parise.

CAs 9 1.-Mr. D. 52 years of age, was attacked, without any evident canse, with a violent sciatica on the right side. The pain was intolerable; leeches ap. plied along the course of the nerve, the use of emollients and rest procured some selief. Mr. D. fancied himself cured, but on attempting to walk, the pain again became so violent that he could scarcely set his right leg to the ground, he, therefore, rather dragged than made any use of it. A multitude of remedies which he tried were all found unavaling.

The patient had been three months in this state when M. Parise saw lim. Desiring to try, in a positive manner, the virtues of the oil of torpentine, which had gained such repute in England, for curing sciatica, II. P. began by administering it in doses gradually increased from a drachm to three drachma a day; this medicine in a few days had a very marked beneficial effert; the patient was so well as to venture ont, but although he walked will all care, the pain returned with augmented intensity. In vain were repeated doses of oil of turpentine swallowed with the view of allaying the patient's sufferings; the effects of the medicine did not answer expectation; and heat and dryness of the throat supervening, with pain of stomach, and violent cholic, compelled its relinquishment. It was then that recourse was had to the method recommended by Cotunims,--a large blister was applied to the outer and lower part of the knee, over the head of the fibula. The patient experienced no very considerable relief, until the eighth day; by the twentieth, however, he was entirely well, and from this time to the present, (about two years,) the complaint has not returned. During the course of the treatment, great care was taken to keep thc bowels properly open, either by the nse of injections or by the repeated administration of the castor oil.

There are several other cases detailed, in which, by pursuing the same plan, relief was much more speedily obtained than in the one we have given. M. P. prefers keeping up suppuration from the blistered part for some time to repeated blistering; the latter not appearing to him to answer so good an end as the former. $\mathrm{He}$ also deems it essentially necessary to success to maintain the belly gently open.

Considerations on certain changes in colour of the cineritious substance of the brain, by M. Biliard.

Every day it becomes more rare to fail in discovering traces of organic lesion in the bodies of those who have fallen victims to acute disease. How common nsed it not to be, in reading the histories of postmortem examinations of individuals who had died insane, to find such phrases as the following:- the brain was healthythere were no traces of disease in the brain? But the better information of the present day frequentiy brings to light organic changes, where, but a few years ago, nothing extraordinary would have been detected. In fact, it is not enough to look merely for changes of texture; alterations in colour and in general appearance are also to be carefully noted. Already Rostan and Lallemand had observed various alterations in the colont of the cerebral parts surrounding points which had suffered in their texture; 11. Billard has now gone farther, and given us some very interesting cases, in which the entiue cineritions substance of the 